\title{
Value of histochemical reactions for mucosubstances in the diagnosis of certain pathological conditions of the colon and rectum
}

\author{
M. ISABEL FILIPE \\ From the Department of Clinical Histochemistry and Cytology, Westminster \\ Medical School, London
}

The histopathologist quite often faces diagnostic problems such as the recognition of early stages of disease, borderline cases, and morphologically atypical pictures which are not always solved by the usual laboratory techniques. Recent histochemical advances in identifying different classes of mucosubstances give more tools which can usefully be applied to solve some of these diagnostic difficulties.

Other authors working in this field have already shown the value of these techniques not only for diagnostic purposes but also for the understanding of the physiological processes in human secretory epithelia and their variations in disease (Lev, 1966; Tellem, Nedwich, Amenta, and Imbriglia, 1966; Greco, Lauro, Fabbrini, and Torsoli, 1967; Hukill and Vidone, 1967; Esterly and Spicer, 1968).

By applying a variety of histochemical techniques to some pathological conditions of the colon and rectum an attempt has been made to draw a map of the mucosubstances present in different diseases and to find a 'trait' which could be an aid to morphological diagnosis.

\section{MATERIAL AND METHODS}

The material studied was obtained from surgical specimens from cases of ulcerative colitis, Crohn's disease, non-specific inflammations, diverticulitis, and benign and malignant tumours of the colon and rectum. Normal colonic and rectal specimens were used as controls (Table I).

Whenever possible, several pieces of tissue from the caecum, the ascending colon, descending colon, and the rectum were taken from each specimen of ulcerative colitis and Crohn's disease. In every case of carcinoma pieces were taken from normal mucosa more than $5 \mathrm{~cm}$ away from the tumour, from normal mucosa on the edge of the tumour, and from the tumour itself.

The tissues were fixed in $10 \%$ formol saline, embedded in paraffin, and cut at $5 \mu$. Sections were stained with haematoxylin and eosin, and the following histochemical methods were performed on paraffin-embedded material
TABLE I

DISTRIBUTION OF CASES AFTER APPLYING METHODS FOR CHARACTERIZING MUCOSUBSTANCES

Histological Diagnosis No. of Cases

Rectum

Normal

Benign epithelial tumours

Malignant epithelial tumours

Non-specific mucosal inflammation

Ulcerative colit is

Colon

Crohn's disease

Normal

Benign epithelial tumours

Malignant epithelial tumours

Non-specific mucosal inflammation

Ulcerative colitis

Crohn's disease

Diverticulitis

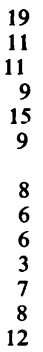

for the characterization of the different mucosubstances (Table II): the periodic-acid-Schiff (PAS) method after McManus (see Pearse, 1960) with and without previous diastase digestion $(1 \%$ malt diastase in physiological saline for one hour at room temperature); Hale's colloidal iron method (1960); hyaluronidase digestion using a $0.05 \%$ solution of bovine testicular hyaluronidase in $0.1 \mathrm{~N}$ acetate buffer at $p \mathrm{H} 5.0$ for three hours at $37^{\circ} \mathrm{C}$ (Hukill and Vidone, 1967); neuraminidase digestion using $0.05 \%$ solution of purified Vibrio cholerae neuraminidase (British Drug Houses) in $0 \cdot 1 \mathrm{~N}$ acetate buffer at $p \mathrm{H} 5 \cdot 5$ for 24 hours at $37^{\circ} \mathrm{C}$ (Hukill and Vidone, 1967) respectively followed by Hale's colloidal iron method; aldehyde fuchsin-alcian blue sequence (Spicer and Meyer, 1960); alcian blue (at $p \mathrm{H}$ 2.5)-PAS method (Mowry and Morard, 1957) with and without previous treatment with neuraminidase; methylation for one hour at $60^{\circ} \mathrm{C}$, followed by alcian blue $(p \mathrm{H} \mathrm{2.5)}$, and PAS stain (Spicer and Lillie, 1959); methylation followed by saponification (Spicer and Lillie, 1959) and stained by alcian blue at $p \mathrm{H} 2.5$ and PAS; alcian blue at $p \mathrm{H} 0.5$ (Lev and Spicer, 1964); high iron diamine-alcian blue method with and without periodate oxidation (Spicer, 1965) and strong methylation (four hours at $60^{\circ} \mathrm{C}$ ) followed by high iron diaminealcian blue method. 
TABLE II

HISTOCHEMICAL METHODS USED FOR VISUALIZING MUCOSUBSTANCES

Method

Periodic-acid-Schiff (PAS)

Diastase-PAS

Alcian blue ( $p H$ 2.5)-PAS

Mild methylation-alcian blue-PAS

Saponification-alcian blue-PAS

Colloidal iron

Hyaluronidase-colloidal iron

Aldehyde fuchsin-alcian blue

Alcian blue, $\mathrm{pH} 0.5$

High iron diamine-alcian blue

Strong methylation-high iron diamine-alcian blue

Neuraminidase-colloidal iron

Neuraminidase-alcian blue-PAS $\}$

RESULTS

For the identification of the mucosubstances we follow, in general, the classification suggested by Spicer, Leppi, and Stoward (1965) and by Leppi and Spicer (1966). The histochemical characteristics of the mucosubstances found in colonic and rectal mucosa in this study can be summarized as follows.

NEUTRAL MUCOSUBSTANCES These are all periodatereactive, giving a positive PAS reaction and showing no modification after diastase digestion.

ACID MUCOSUBSTANCES These stain blue with the

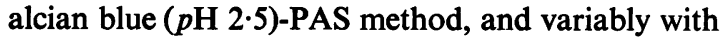
the colloidal iron method. The high iron diamine and alcian blue method stains the sulphated acid mucosubstances brown and the non-sulphated blue. They are resistant to hyaluronidase and to digestion by Vibrio cholerae sialidase. Only a small percentage shows weak susceptibility to sialidase digestion, and is periodate reactive. Mild methylation (one hour at $60^{\circ} \mathrm{C}$ ) hardly affects the alcian blue basophilia but strong methylation (four hours at $60^{\circ} \mathrm{C}$ ) removes all acid mucins stained by the high iron diaminealcian blue method. The aldehyde fuchsin-alcian blue sequence and alcian blue at $p \mathrm{H} 0.5$ did not show consistent results.

NORMAL MUCOSA The 'mucous pattern' (Fig. 1) in normal mucosa shows a predominance of sulphated mucosubstances occupying from the lower third to the whole of the crypt. Non-sulphated acid mucins are usually present in the upper part of the crypt. In the surface epithelium both types of acid mucins are present but one or the other predominates.
Substances Visualized

Glycogen; neutral mucosubstances

Loss of PAS reactivity in sites containing glycogen

Neutral mucosubstances, magenta

Acid mucosubstances, blue

Carboxyl groups of acid mucosubstances lose basophilia after methylation and regain it after saponification.

Acid mucosubstances

Removes hyaluronic acid from acid mucosubstances.

Sulphated mucosubstances: purple;

Non-sulphated acid mucosubstances: blue

Sulphated acid mucosubstances

Sulphated mucosubstances: black-brown

Sialomucins: blue

Stain of all acid mucosubstances occluded

Removes sialic acid from mucosubstances.

Goblet cells in the surface epithelium and/or in the upper part of the crypt may be filled either with sulphated or non-sulphated mucins or the two types of mucin may be found in the same cell. In the latter instance it was usually observed that the nonsulphated material was in the zone between the nucleus and the goblet itself (presumably Golgi area) and at the periphery of the goblet, while the sulphated material occupied the centre of the goblet up to the luminal border.

In most specimens moderate amounts of neutral mucosubstances are also present in the surface epithelium and in the upper crypt.

The pattern described is broadly similar in rectal and colonic mucosa.

'TRANSITIONAL MUCOSA' The mucous membrane immediately adjacent to the edge of a tumour, which

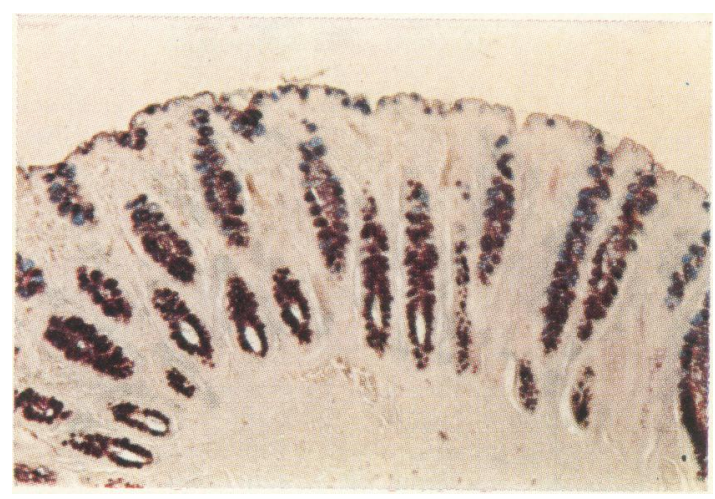

FIG. 1. Normal rectal mucosa. Distribution of sulphated (brown) and non-sulphated (blue) acid mucins using high iron diamine-alcian blue $(\mathrm{pH} 2.5)$ method $\times 25$. 


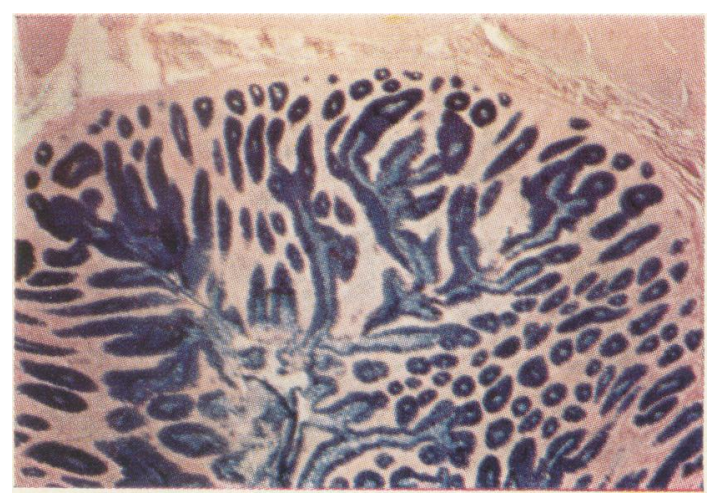

FIG. 2. 'Transitional' rectal mucosa showing a zone of oversecretion of non-sulphated acid material. High iron diamine-alcian blue $(\mathrm{pH} 2.5)$ method $\times 10$.

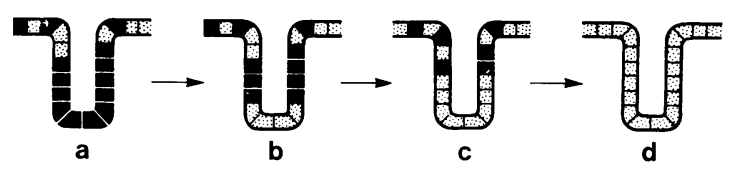

FIG. 3. Diagram of rectal crypt and surface epithelium to show (a) the normal mucous pattern; $(b)$ and $(c)$ the gradual decrease of sulphated material in the mucosa adjacent to tumours and its substitution by a non-sulphated product in the 'transitional' mucosa $(d) ; \square$ sulphated mucin; $\square$ non-sulphated mucin. does not show any microscopic features of malignancy, is called 'transitional mucosa'.

Histochemically the 'mucous pattern' described above in normal mucosa changes both qualitatively and in most cases quantitatively in the mucosa adjacent to tumours. There is a gradual decrease of sulphated material which then is substituted by a non-sulphated product (Fig. 3). This process starts in the lower crypt, while in the upper crypt goblet cells are still filled with sulphated material; nearer the tumour goblet cells all along the crypt and in surface epithelium contain mainly non-sulphated acid mucins (Fig. 2). This was found in every case of carcinoma of the rectum and colon.

It is interesting to note that only two exceptions to the 'normal mucous pattern' were found: one was in a case in which the edges of the surgical resection were only $1.5 \mathrm{~cm}$ from the tumour and the other in which, although the edge was morphologically free from tumour, the section showed vascular tumour emboli, but even in this case, although most of the secretory material in the crypts was non-sulphated acid mucin, the lowest quarter of the crypt showed sulphated material only. In this case another section taken from the other edge of the surgical resection was examined which confirmed the "normal mucous pattern'.

Apart from these qualitative changes, in most cases there are also quantitative differences in the content of mucus. Two zones are usually observed

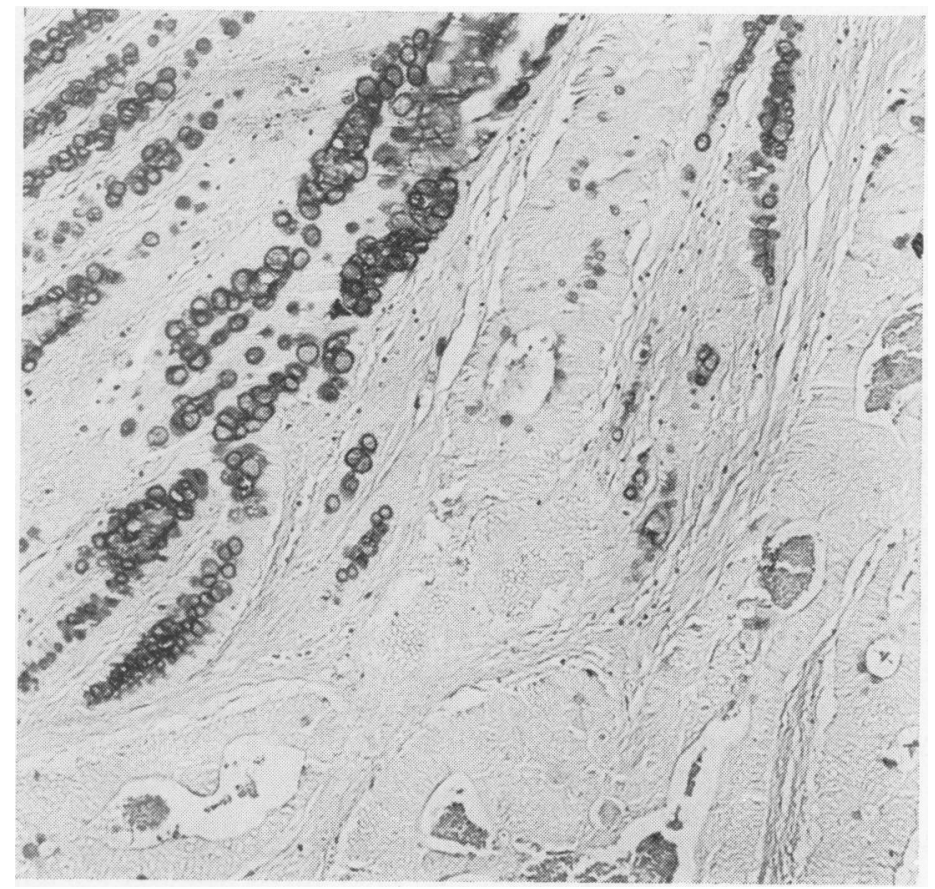

FIG. 4. 'Transitional' rectal mucosa showing a zone of scanty secretion of non-sulphated acid material (left) close to the tumour (right). High iron diaminealcian blue $(\mathrm{pH} 2 \cdot 5)$ method. $\times 80$. 


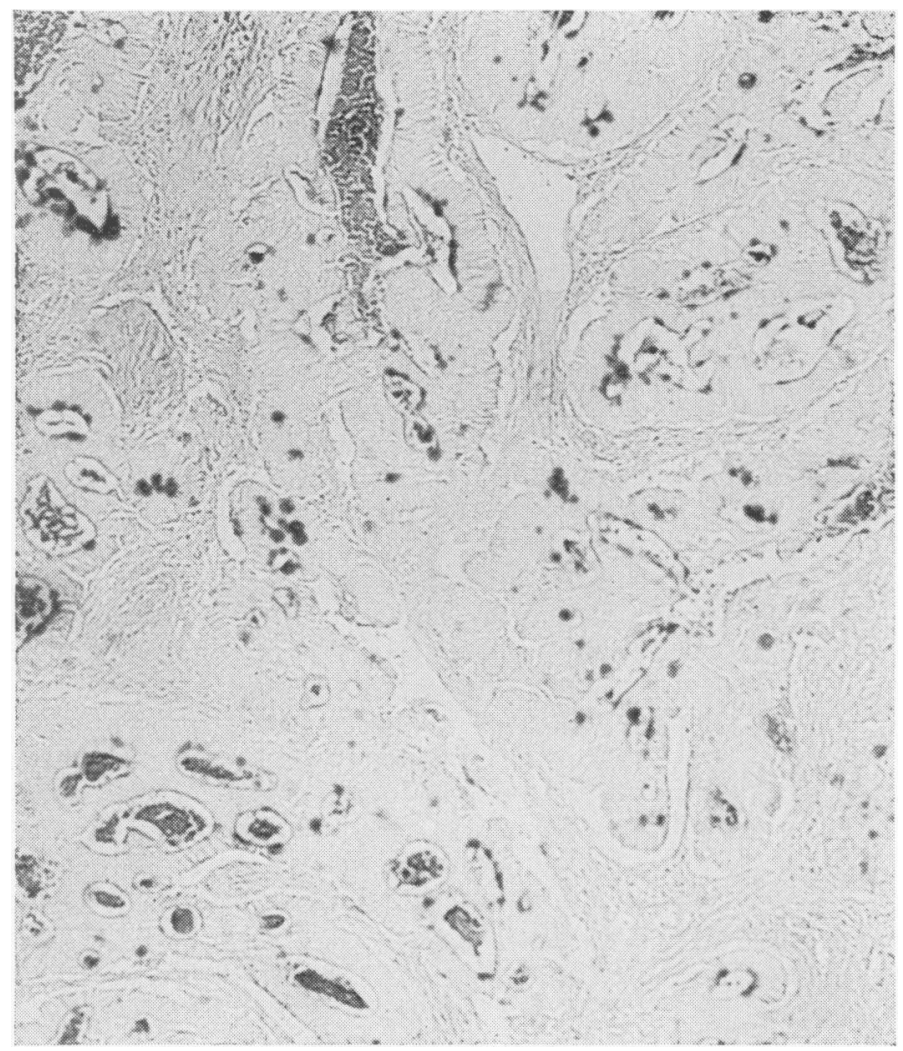

FIG. 5. Adenocarcinoma of rectum. Scanty mucous production is found in occasional goblet cells and in the lumen of gland-like structures. Alcian blue $(\mathrm{pH}$ 2.5)-PAS method. $\times 64$.

in the 'transitional mucosa': one zone with long and dilated crypts, many and large goblet cells, and 'oversecretion' of non-sulphated acid material (Fig. 2) with increased production of neutral mucosubstances in relation to normal; and another zone between this area and the tumour itself, usually narrow, with short crypts, practically no goblet cells, and with very weak or no secretory activity (Fig. 4).

MALIGNANT TUMOURS In adenocarcinoma the cells usually show no secretory elements. Only occasional goblet cells are found which are generally empty or show a 'ring' of stained material at the periphery. In papillary tumours some secretory cells can be seen in more differentiated papilli; also variable amounts of mucous material can be present in the lumen of gland-like structures in more differentiated adenocarcinomas (Fig. 5). The secretory product in all of these is mainly neutral mucosubstances mixed with some non-sulphated and occasionally sulphated mucins.

BENIGN EPITHELIAL TUMOURS The different histochemical characteristics of mucus produced in the benign tumours studied agreed quite well with the different morphological types of polyps. Three main histochemical groups were observed.

Group 1 Histologically these are metaplastic polyps. Histochemically the mucus produced is qualitatively similar to that of normal mucosa (sulphated mucins in the lower crypt and nonsulphated and neutral in the upper crypt and surface epithelium). It differs from the latter quantitatively (usually more mucus is produced) and varies in the relative amounts of sulphated, non-sulphated, and neutral mucosubstances.

Group 2 Morphologically these are adenomatous polyps. Histochemically the characteristics are the heterogeneous mucus produced both qualitatively and quantitatively from zone to zone. Generally there is a moderate amount of secretion but less than in group 1. In papillary tumours, the upper part of the papilli shows less secretory material than the middle zone. In the lower zone the activity is variable from very weak to marked. Sulphated mucosubstances predominate.

Group 3 Morphologically these are adenomatous polyps as above, but show more dedifferentiation. 


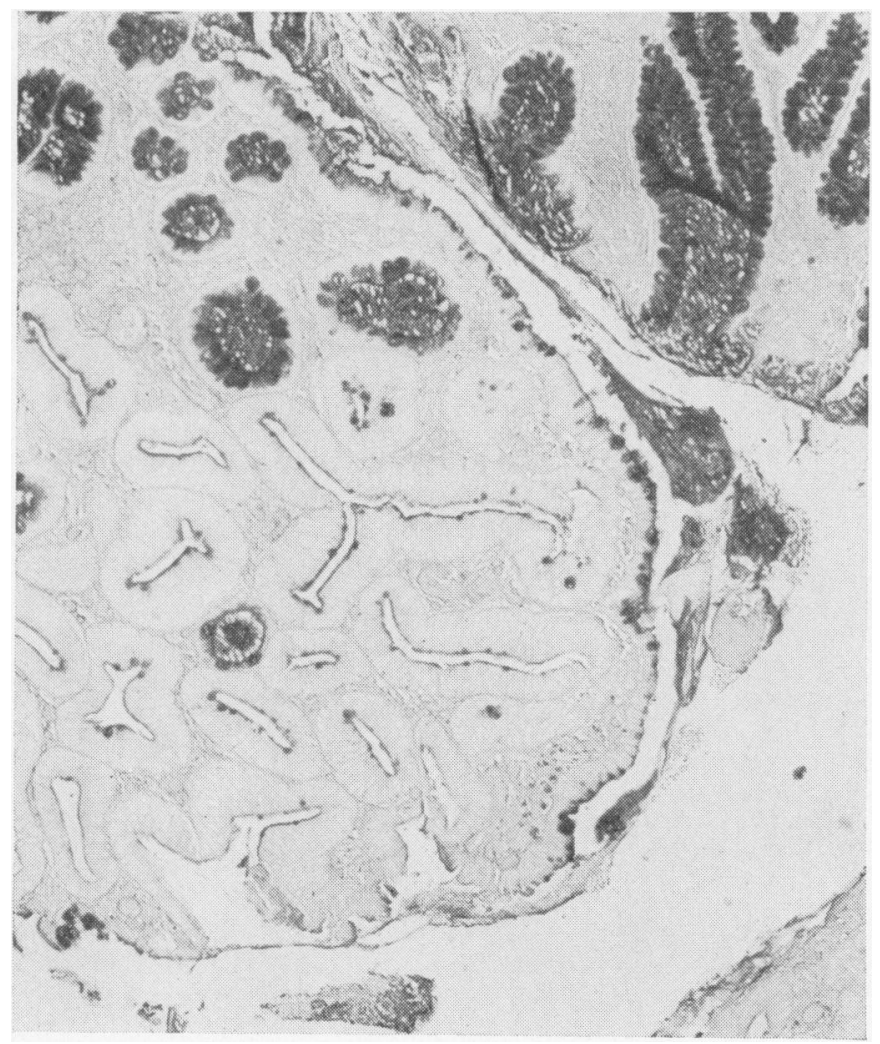

FIG. 6. Adenomatous polyp of rectum showing an area of malignant transformation with practically no mucous secretion. Colloidal iron method. $\times 64$.

Histochemically little or no mucus is produced, the amount varying from zone to zone. Very few goblet cells are found, most being empty, so the secretory activity is shown as a 'ring' at the periphery of the cell or as fine granulations near the luminal border of the crypts. The scanty secretion is mainly of sulphated mucins. Areas of malignant transformation in some of these polyps show either no secretion (Fig. 6) or scanty secretion which is a mixture of sulphated, non-sulphated, and neutral mucosubstances in fine granulations or 'rings' as described above.

INFLAMMATORY CONDITIONS The other group of pathological conditions investigated were inflammatory processes, including non-specific inflammations, ulcerative colitis, and Crohn's disease.

Non-specific inflammations In rectal mucosa the general characteristics of mucous secretion are less mucus produced than normal, variable from zone to zone, from moderate to nearly absent in severely inflamed zones. There are no definite differences in the types of mucosubstances in the upper and lower crypts. There is an irregular mixture of the three types of mucosubstance all along the crypt, pre- dominantly the non-sulphated. Neutral mucosubstances are present in normal or slightly increased amounts.

The secretory product does not usually fill the large goblet cell, but more often is present as fine granulations near the luminal border of the crypt, or in the Golgi area, or as a 'ring' at the periphery of an empty goblet cell (Fig. 7).

The three cases of non-specific acute inflammation of colonic mucosa do not follow exactly the changes described in the rectum. Despite the heavy inflammatory infiltration, there is no marked decrease in mucous secretion and in some areas there are even larger amounts of mucosubstances than normal, in an irregular mixture all along the crypt.

Ulcerative colitis In nine out of 15 cases of ulcerative colitis the secretory activity in the rectal mucosa was practically absent in surface epithelium and varied in the crypts from weak or absent to moderately reduced (Fig. 8). There are a few goblet cells which are only partially filled with mucus. The secretory product is mainly in the form of granulations near the luminal border of the crypt cells. The main substance present is non-sulphated. Small amounts of sulphated mucins may be found, 


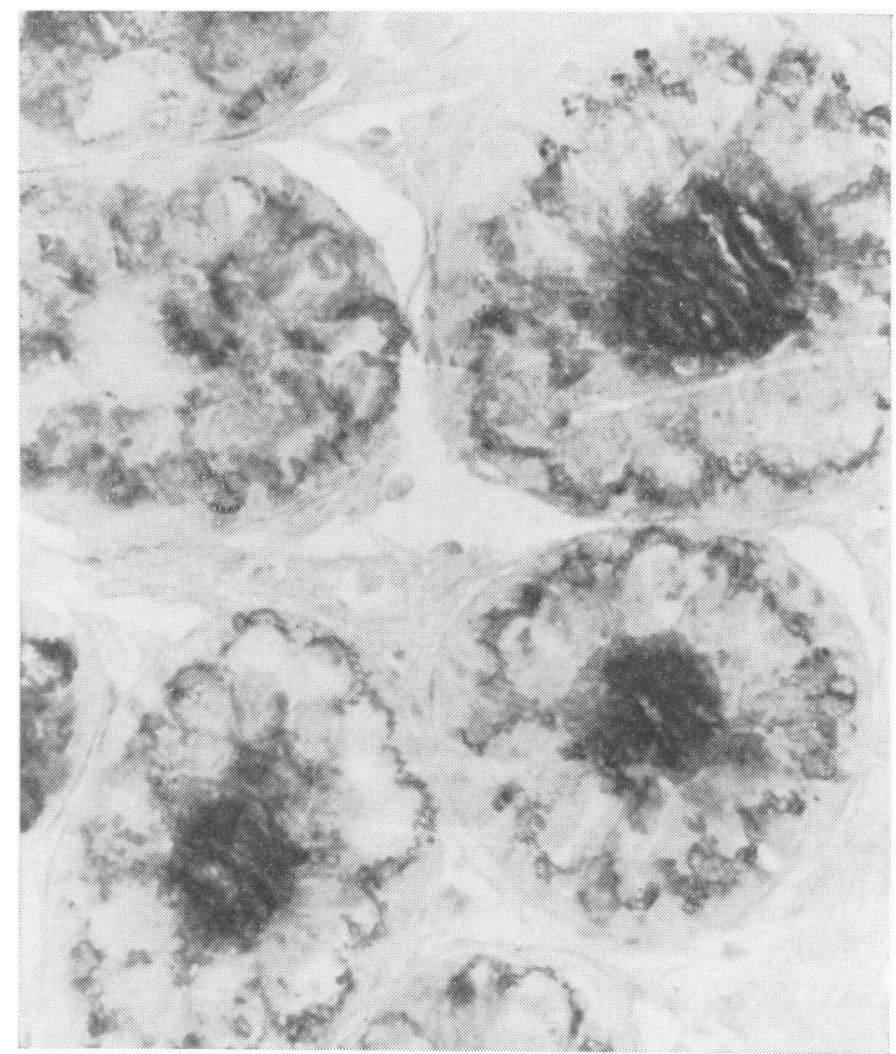

FIG. 7. Non-specific inflammation of rectal mucosa to show the secretory product in the Golgi area and as a 'ring' at the periphery of an empty goblet. Colloidal iron method. $\times 640$.

FIG. 8. Ulcerative colitis in rectal mucosa. The secretory activity is practically absent in surface epithelium and varies in the crypts from weak or absent to moderate. High iron diaminealcian blue $(\mathrm{pH} 2 \cdot 5)$ method $\times 100$.

FIG. 9. Crohn's disease in rectal mucosa showing a normal mucous pattern. High iron diamine-alcian blue $(\mathrm{pH} \mathrm{2.5)}$ method. $\times 100$.

FIG. 7
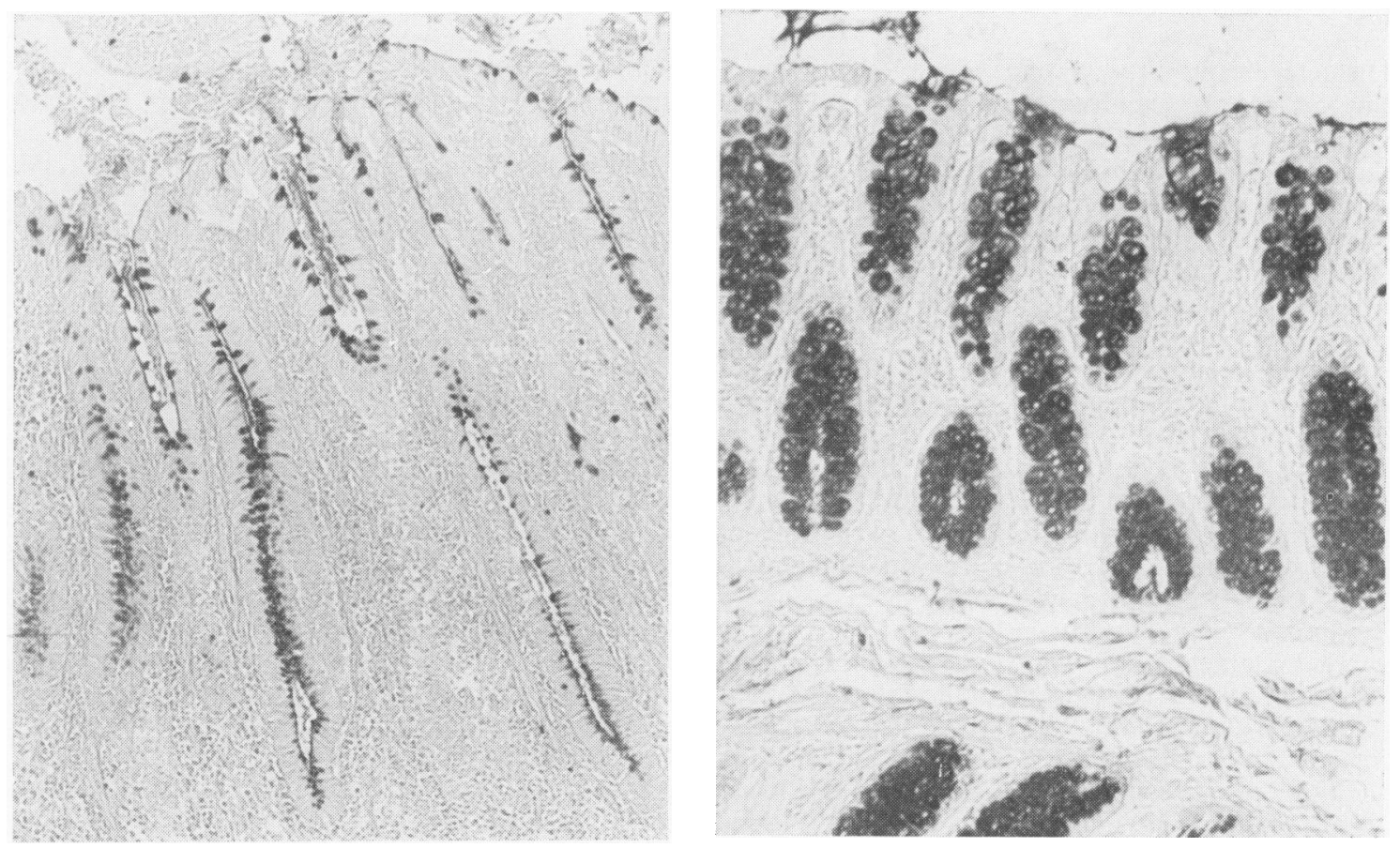

FIG. 8

FIG. 9 
mainly in the bottom of the crypts, and amounts of neutral mucosubstances are decreased or absent.

The six other cases showing a moderate secretory activity were found to be 'quiescent' ulcerative colitis or chronic ulcerative colitis with mild inflammation; one of them showed an atypical morphological picture, with pseudopolypoid formation and large pools of mucin.

Mucous secretion in colonic mucosa in ulcerative colitis is less affected than in the rectum. The mucous composition changes from case to case and in the same case from zone to zone, being either predominantly sulphated, or non-sulphated, or the two types mixed along the crypt.

Crohn's disease In Crohn's disease a marked difference was found in rectal mucosa compared with ulcerative colitis. Moderate to marked mucous secretion was present in all cases except in the zones near ulceration (Fig. 9). Qualitatively a normal 'mucous pattern' was found, or non-sulphated mucosubstances were present alone, or an intermediate pattern could occur.

In the colon the differences between Crohn's disease and ulcerative colitis are not so striking as in the rectum: the amount of mucus was about normal in all cases, and only decreased in zones near ulceration. Again, all sorts of combinations of sulphated and non-sulphated acid mucins were found in crypts. Neutral mucosubstances were present in small amounts or occasionally absent.

Diverticulitis The mucosa of both crypts and surface epithelium shows a similar 'mucous pattern' to normal mucous membrane.

\section{DISCUSSION}

The histochemical characteristics of epithelial mucins vary considerably all along the normal human gastrointestinal tract.

In the stomach, neutral mucosubstances are predominant and sialomucins are also present in smaller amounts (Lev, 1966; Goldman and Ming, 1968), whereas the small intestine contains mainly non-sulphated acid mucins (Lev and Spicer, 1965); sulphomucins are the main product in the columnar cells of the gall bladder and a mixture of the two types of acid mucins is found in the glands (Esterly and Spicer, 1968).

In all specimens of normal colon and rectum a predominance of sulphomucins occupying most of the crypt cells from the lower third to the whole crypt was observed; carboxymucins were also present in the upper crypt and surface epithelium. Similar observations are reported by others (Greco et al, 1967; Goldman and Ming, 1968). A different distribution of the two types of acid mucins present in the colon is described by Lev and Spicer (1965) who found cells containing sulphomucins more numerous in the upper half of the crypt, whereas carboxymucin-reactive cells predominated in the deeper half. No explanation for this difference in distribution is offered.

Histochemically, the acid mucosubstances present in our specimens did not show strong PAS reactivity. Blockage of the mixed high iron diamine staining by previous periodate oxidation was absent or slight which indicates that most of the acid mucins were periodate-unreactive. The weak PAS reactivity of the colonic acid mucins may be due to a low content of fucose (Lev and Spicer, 1965). The histochemical observations correlate quite well with biochemical studies on the acid mucopolysaccharide composition of human colon which reveal the presence of a high percentage of sialic acid and also glucosamine, galactosamine and fucose, and nonacid mucopolysaccharide carbohydrate material (Sky-Peck, Lundgren, and Bornstein, 1966). Connective tissue probably accounts for the chondroitin sulphate, susceptible to hyaluronidase digestion, found by Sky-Peck et al (1966), since hyaluronidase treatment of sections in this study removed the colloidal iron staining from the acid mucosubstances in the connective tissue leaving the epithelial acid mucins unchanged. Other biochemical analyses reveal that in addition to mucoproteins containing sialic acid and fucose, sulphated mucopolysaccharides were present in the colon (Werner, 1953).

The presence of sulphated material in the intestinal goblet cells has been further demonstrated by autoradiographic techniques which show the Golgi region to be the site of the synthesis and sulphation of complex carbohydrates (Lane, Caro, OteroVilardebó, and Godman, 1964; Peterson and Leblond, 1964; Neutra and Leblond, 1966; Wetzel, Wetzel, and Spicer, 1966; Berlin, 1967).

The fact that most of the goblet cells in the surface epithelium and upper crypt contain non-sulphated mucins (only a small number show sulphated material and in some the two types of acid mucins are mixed) can possibly be explained by the formation in these cells of two polymers, or one polymer with varying proportions of sialic acid and ester sulphate (Spicer and Sun, 1967). The process of maturation and aging of the epithelial cells as they migrate from the bottom of the crypts towards the upper crypt and surface epithelium could be responsible for the qualitative changes in mucin produced, from sulphomucins (in lower crypt goblet cells) to non-sulphated mucins (in upper crypt and surface epithelium). Qualitative changes in mucus have been found in the epithelial cells of the 
bronchi in children according to age (Reid, personal communication) and in other tissues in relation to cell maturation (Wetzel et al, 1966).

In the morphologically normal colonic and rectal mucosa adjacent to the tumour a process of gradual substitution of sulphated material by a nonsulphated substance was observed, starting in the goblet cells in the deeper crypt while the goblet cells in the rest of the crypt were still filled with a sulphated material, which seems to confirm further the migration theory (Leblond and Messier, 1958; Cole and McKalen, 1961). Finally in the 'transitional' mucosa close to the tumour all goblet cells in the crypts contain mainly non-sulphated acid mucins. A similar qualitative change in mucous production in the mucosa in the edge of the tumours is reported in the gall bladder (Esterly and Spicer, 1968) and in the stomach (Lev, 1966).

This non-sulphation in colonic and rectal mucosa near carcinomas postulates several hypotheses and various factors may play some part. The failure of sulphation might be due to (1) extracellular factors when no sulphate is available to the epithelial cells due to blockage of one or more of the barriers sulphate has to pass from the bloodstream to the epithelial cell membrane, $i e$, changes in connective tissue and blood vessel wall mucopolysaccharides which have been described near tumours by Majewski, Tkaczyk, and Majewski, 1966; or to (2) intracellular factors, ie, enzymatic change. It is possible that adenosinetriphosphatase may be responsible for the transport mechanism of sulphate through the goblet cell membrane (Otero-Vilardebó, Lane, and Godman, 1964), and it has been assumed that sulphation requires a high energy bond and takes place by transfer of sulphate from phosphoadenosine phosphosulphate to mucopolysaccharides and other acceptors (Lane et al, 1964).

Histochemical enzymatic studies by Wattenberg (1959) on proliferative lesions of the large intestine reveal quantitative and qualitative changes in succinic dehydrogenase and cytochrome oxidase in atypical glands found in malignant polyps and in other benign proliferative lesions which the author thinks may constitute an early indication of carcinogenesis. Similar changes were observed in this study (unpublished data) with succinic dehydrogenase, glucose-6-phosphate dehydrogenase, and NAD and NADP diaphorases which show in the crypt cells near tumours a disruption of the usual intracellular distribution of the final enzymatic reaction product.

These changes in the mucosa close to tumours pose further problems. Are these enzymatic changes specific or non-specific? Are they responsible for the failure of sulphation in the goblet cells? Is this non- sulphation a cause or a consequence of malignant transformation, or, in other words, is it because cells undergo malignant transformation that they lose the capacity for sulphation or is the lack of sulphation due to non-specific factors which induce proliferation? These mechanisms are not yet understood. Mucopolysaccharides seem to play a role in the initiation and control of cell division, and cells or tissues where the mucopolysaccharide block is absent exhibit active proliferation (Lippman, 1965). Several factors, such as radiation, virus, injury, hormones, changes in available calcium ion, lack of environmentally supplied mucopolysaccharides, etc, may alter the stability of the mucopolysaccharidecalcium complex in the cell and so initiate division (Bo, Smith, Reiter, and Pizzarello, 1965; Lippman, 1965). Sulphated mucopolysaccharides also play an important protective role in the gastric mucosa, either by forming a complex with gastric mucus, increasing its viscosity and then enhancing the protective properties of the mucous barrier, or by a direct inhibitory effect on peptic activity (Sun, 1967).

On the other hand, a number of sulphated polysaccharides are known to block cell division. A marked inhibition of tumour growth was obtained by intraperitoneal injection in mice bearing the Ehrlich ascites tumour of a preparation from follicular fluid from sow ovaries rich in acid mucopolysaccharides (Lippman, 1965).

The mucosubstances found in adenocarcinoma of the colon and rectum show nothing characteristic, which agrees with the results obtained by Goldman and Si-Chung Ming (1968) and by Beaupain and Wolff (1967) in tissue culture from an adenocarcinoma of the colon.

In this study mucosubstances in large intestinal tumours have not been a help in the differential diagnosis of metastases among other mucin-producing tumours (Garcia-Bunuel and Monis, 1964; Lev, 1966; Hukill and Vidone, 1967; Esterly and Spicer, 1968).

No general pattern of mucosubstances in benign tumours as described by Goldman and Si-Chung Ming (1968) was found. In view of our results, benign tumours have to be considered according to their histological types which show histochemically different characteristics of mucous secretion.

Autoradiographic techniques (Cole and McKalen, 1963) and experimental work on the morphogenesis of adenomatous polyps of the large intestine will certainly help to correlate the different mucinproducing zones in these polyps with the rate of proliferation and their possible malignant transformation.

Qualitatively both sulphated and non-sulphated acid mucins are present in variable amounts and 
distribution in non-specific inflammations, ulcerative colitis, and Crohn's disease. On this basis it is not therefore possible to make a differential diagnosis between these three conditions. This non-specific qualitative heterogeneity of mucins can probably be explained either by environmental changes due to the inflammatory infiltrate, haemorrhage, etc, or by a more rapid renewal of the epithelial cells of the crypts in some areas.

On quantitative grounds some differences were recognized. Neutral mucosubstances in non-specific inflammations are present in normal or slightly increased amounts and in Crohn's disease and ulcerative colitis they are decreased or absent.

In relation to acid mucosubstances, non-specific inflammations containing variable amounts of the two types of mucin cannot be quantitatively differentiated from the other two conditions. On the other hand, material from cases of Crohn's disease shows a normal amount of mucus compared with the small amount usually present in ulcerative colitis; so, if a small amount of mucus is found, it is most probable that the disease is ulcerative colitis rather than Crohn's disease. The converse is not true. This applies mainly to the rectum in which the differences in mucous secretion between ulcerative colitis and Crohn's disease are usually striking. In the colon, the differences are not marked. Contrary to the view of Hellstrom and Fisher (1967), the histochemical methods for mucosal mucin used in this study do not always represent a valid method for the distinction of these two conditions, especially in colonic specimens. In some cases of chronic longstanding ulcerative colitis amounts of mucus in colonic mucosa similar to those in Crohn's disease were found.

In areas of pseudopolypoid formation in chronic ulcerative colitis, an increase of mucus referred to by others (Hellstrom and Fisher, 1967) was also observed in the material studied here.

\section{SUMMARY}

Histochemical methods to visualize neutral mucins and sulphated and non-sulphated acid mucosubstances were used in various pathological conditions of the large intestine and rectum. The material, obtained from surgical specimens, included benign and malignant tumours, non-specific inflammations, ulcerative colitis, Crohn's disease, and diverticulitis.

In normal rectal and colonic mucosa the 'normal mucous pattern' shows a predominance of sulphated acid mucosubstances occupying most of the crypt cells, non-sulphated acid mucosubstances usually being present in the upper crypt, and the two types of acid mucosubstance, usually mixed, in the surface epithelium. Neutral mucosubstances can be found in the upper crypt and surface epithelium. Qualitative and quantitative changes were observed in the normal mucosa close to the tumour (transitional mucosa) and two zones can be described: a zone of oversecretion containing only non-sulphated acid mucosubstances and another zone in closer contact with the tumour showing very weak or no secretion. Cells of malignant tumours usually show no secretory elements or only a scanty secretion of mixed neutral, sulphated and non-sulphated mucosubstances. In benign tumours three main histochemical groups were observed which agree quite well with the different morphological types of polyp. Areas of malignant transformation in some of these polyps show practically no secretion.

Qualitatively there are no differences in mucous secretion between non-specific inflammations, Crohn's disease, and ulcerative colitis, but quantitative variations in the amount of mucus were found in these three conditions.

The amount of neutral mucosubstances present is moderate in normal mucosa, moderate or slightly increased in non-specific inflammations, decreased in Crohn's disease, and absent in ulcerative colitis.

The amount of acid mucosubstance is variable in non-specific inflammations, moderate in Crohn's disease, and decreased in ulcerative colitis.

In Crohn's disease a marked difference is found in rectal mucosa compared with that in ulcerative colitis, but in the colon the differences are not so striking.

Mucous secretion in colonic mucosa in diverticulitis is similar to normal mucosa.

The factors which might influence the process of sulphation and the possible role played by sulphated mucosubstances in cell proliferation are discussed.

I am grateful to Professor I. M. P. Dawson for his valuable advice and help in preparing this paper, and to Miss M. O'Connell, Mrs H. Francis, and Miss B. Patel for the technical assistance and Miss J. Ashby for the secretarial work. The Photographic Department of the Westminster Hospital was responsible for all the photographic work.

This investigation was supported by a grant from the British Empire Cancer Campaign.

\section{REFERENCES}

Beaupain, R., and Wolff, E. (1967). Etude histochimique du mucus sécrété par une tumeur maligne du côlon cultivée. C.R. Acad. Sci. (D) Paris, 264, 1953-1956.

Berlin, J. D. (1967). The localization of acid mucopolysaccharides in the golgi complex of intestinal goblet cells. J. Cell Biol., 32, 760-766.

Bo, W. J., Smitn, S., Reiter, R., and Pizzarello, D. J. (1965). The effect of ovarian hormones on the sulphomucopolysaccharides of the uterus. J. Histochem. Cytochem., 13, 461-469.

Cole, J. W., and McKalen, A. (1961). Observations of cell renewal in human rectal mucosa in vivo with thymidine- $\mathrm{H}^{3}$. Gastroenterology, 41, 122-125. 
(1963). Studies on the morphogenesis of adenomatous polyps in the human colon. Cancer (Philad.), 16, 998-1002.

Esterly, J. R., and Spicer, S. S. (1968). Mucin histochemistry of human gallbladder: changes in adenocarcinoma, cystic fibrosis, and cholecystitis. J. nat. Cancer Inst., 40, 1-12.

Garcia-Bunuel, R., and Monis, B. (1964). Histochemical observations on mucins in human ovarian neoplasms. Cancer (Philad)., 17, 1108-1118.

Goldman, H., and Ming, S. C. (1968). Mucins in normal and neoplastic gastrointestinal epithelium: histochemical distribution. Arch. Path., 85, 580-586.

Greco, V., Lauro, G., Fabbrini, A., and Torsoli, A. (1967). Histochemistry of the colonic epithelialmucins in normal subjects and in patients with ulcerative colitis. A qualitative and histophotometric investigation. Gut, 8, 491-496.

Hellstrom, H. R., and Fisher, E. R. (1967). Estimation of mucosal mucin as an aid in the differentiation of Crohn's disease of the colon and chronic ulcerative colitis. Amer. J. clin. Path., 48, 259-268.

Hukill, P. B., and Vidone, R. A. (1967). Histochemistry of mucus and other polysaccharides in tumors. II. Carcinoma of the prostate. Lab. Invest., 16, 395-406.

Lane, N., Caro, L., Otero-Vilardebó, L. R., and Godman, G. C. (1964). On the site of sulfation in colonic goblet cells. J. Cell. Biol., 21, 339-351.

Leblond, C. P., and Messier, B. (1958). Renewal of chief cells and goblet cells in the small intestine as shown by radioautography after injection of thymidine- $\mathrm{H}^{3}$ into mice. Anat. Rec., 132, 247-259.

Leppi, T. J., and Spicer, S. S. (1966). The histochemistry of mucins in certain primate salivary glands. Amer. J. Anat., 118, 833-850.

Lev, R. (1966). The mucin histochemistry of normal and neoplastic gastric mucosa. Lab. Invest., 14, 2080-2100.

-, and Spicer, S. S. (1964). Specific stainirg of sulfate groups with alcian blue at low $p$ H. J. Histochem. Cytochem., 12, 309.

- - (1965). A histochemical comparison of human epithelial mucins in normal and hypersecretory states including pancreatic cystic fibrosis. Amer. J. Path., 46, 23-47.

Lippman, S. S. J. M. (1965). A proposed role for mucopolysaccharides in the initiation and control of cell division. Trans. N.Y. Acad. Sci., 27, 342-357.

Majewski, C., Tkaczyk, J., and Majewski, W. (1966). Acid mucopolysaccharide activity in cancer of the colon and rectum. Pat. pol., 17, 313-319. (Abstr. Excerpta med. (Amst.), Sect.V, 20, no. 1491, 1967).

Mowry, R. W., and Morard, J. C. (1957). The distribution of acid mucopolysaccharides in normal kidneys, as shown by the alcian blue-Feulgen (AB-F) and alcian blue-periodic acidSchiff (AB-PAS) stains. Amer. J. Path., 33, 620-621. (Abstr.).

Neutra, M., and Leblond, C. P. (1966). Synthesis of the carbohydrate of mucus in the Golgi complex as shown by electron microscope radioautography of goblet cells from rats injected with glucose$\mathrm{H}^{3}$. J. Cell Biol., 30, 119-136.

Otero-Vilardebó, L. R., Lane, N., and Godman, G. C. (1964). Localization of phosphatase activities in colonic goblet and absorptive cells. Ibid., 21, 486-490.
Pearse, A. G. E. (1960). Histochemistry: Theoretical and Applied, 2nd ed. Churchill, London.

Peterson, M., and Leblond, C. P. (1964). Synthesis of complex carbohydrates in the Golgi region, as shown by radioautography after injection of labeled glucose. J. Cell Biol., 21, 143-148.

Sky-Peck, H. H., Lundgren, R., and Bornstein, I. (1966). Acid mucopolysaccharide composition in human colon. Ann N.Y. Acad. Sci., 130, 951-962.

Spicer, S. S. (1965). Diamine methods for differentiating mucosubstances histochemically. J. Histochem. Cytochem., 13, 211-234.

-, Leppi, T. J., and Stoward, P. J. (1965). Suggestions for a histo chemical terminology of carbonhydrate-rich tissue components. Ibid., 13, 599-603.

_, and Lillie, R. D. (1959). Saponification as a means of selectively reversing the methylation blockade of tissue basophilia. Ibid. 7, 123-125.

_, and Meyer, D. B. (1960). Histochemical differentiation of acid mucopolysaccharides by means of combined aldehyde fuchsinalcian blue staining. Amer. J. clin. Path., 33, 453-460.

- , and Sun, D. C. H. (1967). Carbohydrate histochemistry of gastric epithelial secretions in dog. Ann. N.Y. Acad. Sci., 140, 762-783.

Sun, D. C. H. (1967). Effect of a synthetic sulfated polysaccharide (SN-263) on gastric peptic astivity in humans. Ibid., 140, 747-753.

Tellem, M., Nedwich, A., Amenta, P. S., and Imbriglia, J. E. (1966) Mucin-producing carcinoma of the breast: tissue culture, histochemical and electron microscopy study. Cancer (Philad.), 19, 573-584.

Wattenberg, L. W. (1959). A histochemical study of succinic dehydrogenase and cytochrome oxidase in proliferative lesions of the large intestine. Cancer Res., 19, 1118-1123.

Werner, I. (1953). Studies on glucoproteins from mucous epithelium and epithelial secretions. Acta. Soc. Med. upsalien, 58, 1-55.

Wetzel, M. G., Wetzel, B. K., and Spicer, S. S. (1966). Ultrastructural localization of acid mucosubstances in the mouse colon with iron-containing stains. J. Cell Biol., 30, 299-315.

\section{ADDENDUM}

Since this paper was submitted, work has been published (Gad, A., 1969, Brit. J. Cancer, 23, 52-68: 'A histochemical study of human alimentary tract mucosubstances in health and disease. I. Normal and tumours; II. Inflammatory conditions') which presents some results broadly similar to my own. In inflammatory conditions and benign tumours of colon and rectum, however, my findings are not entirely in agreement. 